\title{
Letter to the Editor Re
}

\section{Public Reporting of Cost and Quality Information in Orthopaedics}

\author{
Adam M. Ali BA (Cantab)
}

Published online: 11 May 2012

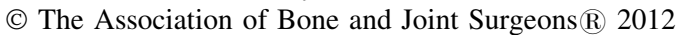

\section{To the Editor}

Marjoua et al. argue that disseminating quality information corrects information asymmetry in healthcare markets and therefore is a "necessary building block in the pursuit of value-based healthcare" [1]. The underlying assumption is that patients will use such information to make an informed choice of provider and as such will drive up quality. However, whereas in a market for most goods a failing product will be abandoned, in healthcare the reality is that failing providers often are left for those who simply are unable to exercise choice, for example, people in lower socioeconomic classes or the elderly. Public outcome reporting may be effective in stimulating quality improvement, but the mechanism for effecting change must be through influencing healthcare providers and not through reliance on patient choice: this is particularly the case in elective orthopaedics where the patient population is elderly and, rather than being savvy to the healthcare market, have confidence in their local provider. Quality control is the responsibility of the medical profession, not of patients.

\section{Reference}

1. Marjoua Y, Butler CA, Bozic KJ. Public reporting of cost and quality information in orthopaedics. Clin Orthop Relat Res. 2012;470:1017-1026.

(Re: Marjoua Y, Butler CA, Bozic KJ. Public reporting of cost and quality information in orthopaedics. Clin Orthop Relat Res. 2012;470:1017-1026.)

Each author certifies that he or she, or a member of their immediate family, has no commercial associations (eg, consultancies, stock ownership, equity interest, patent/licensing arrangements, etc) that might pose a conflict of interest in connection with the submitted article.

All ICMJE Conflict of Interest Forms for authors and Clinical Orthopaedics and Related Research editors and board members are on file with the publication and can be viewed on request.

A. M. Ali $(\bowtie)$

Green-Templeton College, University of Oxford,

Woodstock Road, Oxford OX2 6HG, UK

e-mail: adamali@post.harvard.edu 